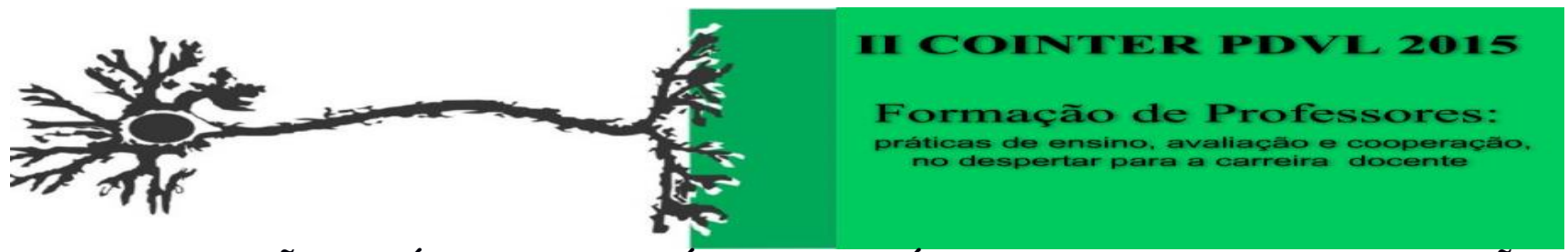

A CONCEPÇÃO DE ÁTOMO NA QUÍMICA, NA FÍSICA E NA BIOLOGIA UMA VISÃO MULTIDISCIPLINAR

\author{
Apresentação: Comunicação Oral
}

Ayrton Matheus da Silva Nascimento ${ }^{1}$; Adrielly Katharine Barbosa Ferreira ${ }^{2}$; Kilma da Silva Lima Viana $^{3}$ Aguinalda Alves Teixeira Filha ${ }^{4}$

RESUMO: Disciplinas como química, física e biologia, trazem em seus currículos, conteúdos que necessitam para sua compreensão, um grande nível de abstração. Outro obstáculo à compreensão é uma abordagem cartesiana, fragmentária e descontextualizada distanciando o conteúdo da realidade de docentes e discentes, tornando o estudo pouco significativo. Trata-se de uma pesquisa de abordagem qualitativa, de campo do tipo descritiva, realizada com alunos do ensino médio do IFPE Campus Vitória, com o objetivo de fazer um levantamento sobre as concepções de átomos a partir da observação de aulas de Química, Física e Biologia, além de entrevistas com discentes do ensino médio. Nas entrevistas os discentes indicaram as disciplinas de química, física e biologia como aquelas responsáveis pelo estudo do átomo e nas aulas observadas o ponto em comum entre os docentes, foi a definição do átomo como partículas indivisíveis, contudo realizando contextualizações inerentes apenas as suas respectivas disciplinas, o que nos leva a concluir a necessidade de abordagens interdisciplinares onde possam se desenvolver uma percepção holística do átomo.

Palavras-chave: átomos, concepção, discentes, docentes, interdisciplinaridade

\title{
INTRODUÇÃO
}

O conceito de átomo é fundamental para a compreensão de vários conteúdos abordados no estudo das ciências. São muitos os conceitos de átomos observados ao longo da história; na atualidade encontramos um conceito comum, onde segundo Atkins e Jones (2006): “o átomo fica sendo definido como a menor partícula de um elemento que tem as propriedades químicas desse elemento". Apesar de ser um conhecimento comum em várias disciplinas observamos que raramente o átomo é estudado de forma contextualizada e interdisciplinar. Nossa pesquisa objetivou realizar um levantamento das concepções de alunos do ensino médio, sobre a concepção de átomos, além de observar como este conteúdo vem sendo abordado nas aulas. Para tanto, realizamos entrevistas com alunos sobre concepções relacionadas aos átomos e observamos algumas aulas das disciplinas de química, física e biologia. Percebemos que a maioria dos alunos atribui o estudo do átomo a disciplina de química primeiramente e depois a outras disciplinas. Na observação das aulas concluímos que este estudo ainda esta sendo realizado de forma fragmentária sem contextualizações

\footnotetext{
${ }^{1}$ Licenciatura em Química, Instituto Federal de Pernambuco (IFPE - CVSA), E-mail ayrthon.matheus@gmail.coml

2 Graduada em Gestão em Segurança do Trabalho, Faculdade Osman Lins (FACOL), E-mail: adrielly.katharine@gmail.com

${ }^{3}$ Docente do Instituto Federal de Pernambuco (IFPE - CVSA), E-mail: kilma.viana@vitoria.ifpe.edu.br

${ }^{4}$ Docente do Instituto Federal de Pernambuco (IFPE - CVSA), E-mail: aguinalda.alves@vitoria.ifpe.edu.br
} 
interdisciplinares. Lembramos que nossa pesquisa foi realizada com o objetivo de obter um levantamento de dados sobre as concepções de átomos com docentes e discentes do ensino médio do IFPE Campus Vitória.

Esta perspectiva é observada em disciplinas obrigatórias ao currículo do ensino médio, como a química, a física e a biologia que estudam o conceito do átomo, com suas respectivas peculiaridades.

Tomando como referência o estudo do átomo, numa perspectiva cartesiana, o discente primeiro teria que estudar a estrutura do átomo, conhecer suas pequenas partes para posteriormente relacioná-los com seu corpo, com reações químicas, fenômenos físicos e depois com o mundo.

\section{FUNDAMENTAÇÃO TEÓRICA}

O paradigma cartesiano-newtoniano, foi configurado pelas ideias de Descartes e de Newton implantando a ordem do pensamento analítico e mecanicista nos confins de nossa cultura, estruturando assim as nossas mentalidades ocidentais modernas.

A hipótese levantada por Descartes de que o universo, o ser humano e a natureza, teriam sua constituição, análoga a de um relógio suíço foi bem aceita pelos cientistas da época (século XVI), e ainda o é, visto que este paradigma (cartesiano), está fortemente representado nas ciências.

A ideia de que o ser humano teria sua constituição similar a de uma máquina - composta de peças, engrenagens e movimentos mecânicos - levantou grande polêmica e admiração, justamente por explicar algo que, até então, se revelava como misterioso e divino: feito a imagem e a semelhança de Deus, o homem, uma vez despido dessa maneira, teria nas mãos a chave para desvendar o enigma da existência; o racionalismo conquistaria um de seus maiores trunfos (Bueno, 2004).

Essa estabilidade adquirida pelos cartesianos, ganha espaço na comunidade científica, pois o objetivo da ciência é o de oferecer cada vez mais segurança e certeza em suas proposições e descobertas.

Este paradigma, portanto, se caracteriza por propor uma visão mecanicista do conhecimento, composto de várias partes menores que se unem e se entrelaçam. Para entender o funcionamento da máquina, é preciso desmontá-la ou dividi-la em suas partes. Isto é, fragmentar para conhecer. Como afirma Capra (1995): 
em suas partes componentes e em dispô-las em sua ordem lógica) levou a uma fragmentação característica do nosso pensamento, em geral, das nossas disciplinas acadêmicas, e levou a atitude generalizada de reducionismo da ciência onde se acredita em que todos os aspectos dos fenômenos complexos podem ser compreendidos se reduzidos às suas partes constituintes.

Essa abordagem fragmentada é responsável pela formação de conceitos fragmentados e descontextualizados por parte do aluno uma vez que os conceitos são estudados de forma isolada, não contemplando abordagens intradisciplinares (inter relacionando conteúdo de uma mesma disciplina) nem tão pouco interdisciplinares (inter relacionando conteúdos de várias de disciplinas).

De acordo com Brasil apud Fortes (2009) a reorganização curricular determinada em áreas de conhecimento, estruturada pelos princípios pedagógicos da interdisciplinaridade, da contextualização da identidade, da diversidade e autonomia, vai redefinir uma relação entre os sistemas de ensino e as escolas. Essa proposta proporciona uma influência mútua entre as áreas curriculares e facilita o desenvolvimento dos conteúdos, numa perspectiva de interdisciplinaridade e contextualização.

\section{MATERIAL E MÉTODOS}

Trata-se de uma pesquisa de natureza quali-quantitativa, de campo de tipo descritiva. Participaram como sujeitos 164 alunos do $1^{\circ}$ ano do curso médio integrado e docentes dos respectivos componentes curriculares do IFPE Campus Vitória de Santo Antão, localizado na zona rural, Propriedade Terra Preta na cidade de Vitória de Santo Antão - PE. Os dados foram coletados por meio de observações das aulas, objetivando identificar as concepções de átomos de docentes em situações em sala de aula e através de um questionário aplicado aos discentes.

As análises dos dados foram realizadas através da análise do conteúdo (BARDIN,2011) categorial por temática que se constitui numa ação de desmembramento do texto analisado em categorias, para posterior reagrupamento em categorias analíticas e empíricas (SOUZA e SOUZA JUNIOR, 2013).

As categorias analíticas trazem uma apreensão do objeto estudado de forma ampla, sendo bases para reflexão teórica do objeto e dados. Enquanto que as categorias empíricas guardam uma relação com o objeto mais operacional, pois advêm dos dados empíricos do campo dos questionários aplicados.

\section{RESULTADOS E DISCUSSÃO}


A análise dos conceitos de átomos demostradas no organograma abaixo em quatro disciplinas, traz em comum, o átomo como partícula indivisível e presente na constituição de toda e qualquer matéria.

Durante a realização das aulas observadas o átomo é citado como partícula essencial e indivisível pelos docentes e discentes caracterizando pontos em comum nas disciplinas de física, química e biologia, denotando-se contextualizações durante as observações das aulas na disciplina de biologia em relação às funções do átomo no corpo humano e na disciplina de química com os fogos de artifício.

Observou-se um consenso entre docentes e discentes no que diz respeito a concordarem que as disciplinas que mais se reportam aos conceitos de átomos são as de física, química e biologia, sendo a química a mais citada.

Quanto ao questionamento sobre a relação dos átomos com as situações diárias observou-se que os estudantes afirmaram que o átomo está relacionado a toda e qualquer situação, o que corroborando para confirmar a percepção do átomo como constituinte de todas as matérias.

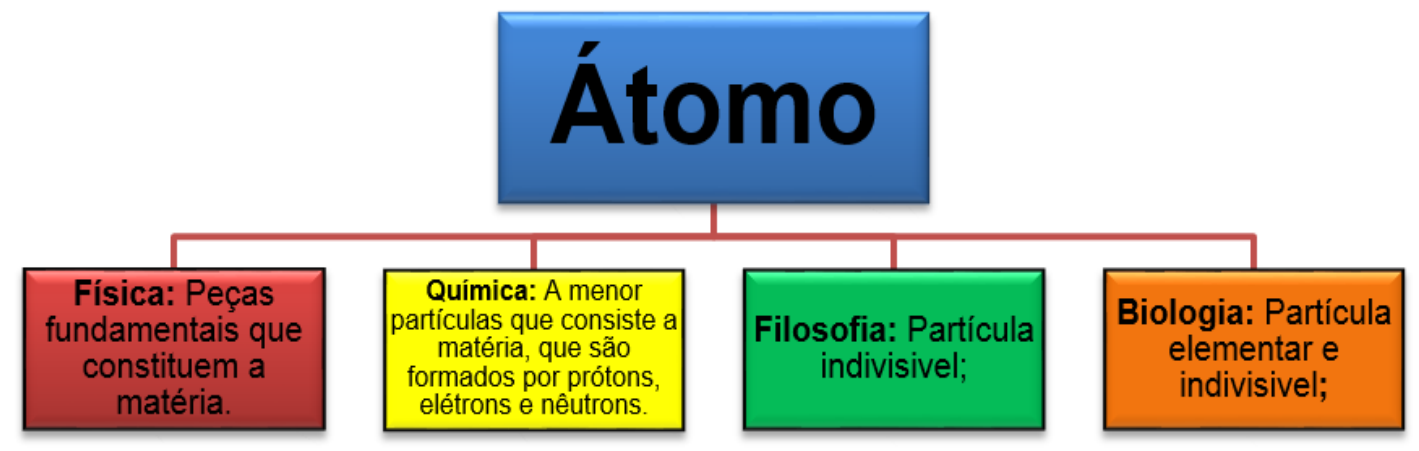

Organograma da definição de Átomo dos professores dos componentes Curriculares

Foi aplicado um questionário aos discentes, com 04 questões a saber: (1) "Em que disciplina você estuda (ou estudou) o átomo?" (2) "Você acha que deveria estudar o conceito de átomo em alguma outra disciplina? Qual ou quais?” (3) “Qual a relação do átomo com o dia-a-dia?” (4) "Qual a sua definição de Átomo?”. Observando o gráfico relacionado à primeira questão podemos perceber que os alunos relacionaram o estudo do átomo principalmente a disciplina de Química, uma vez que é nessa disciplina que estudam o átomo, partindo de suas características e propriedades observadas na tabela periódica, até as diversas substancias e reações. Contudo, ver o átomo apenas ou primeiramente, relacionado à disciplina de química, nos conduz a denotar uma percepção fragmentada por parte do estudante, que na realidade estuda não só o átomo, como substancias e reações químicas em tantas outras disciplinas, e que talvez não o percebam devido à falta de dinâmicas de contextualização e sistematização dos conteúdos e conceitos. 


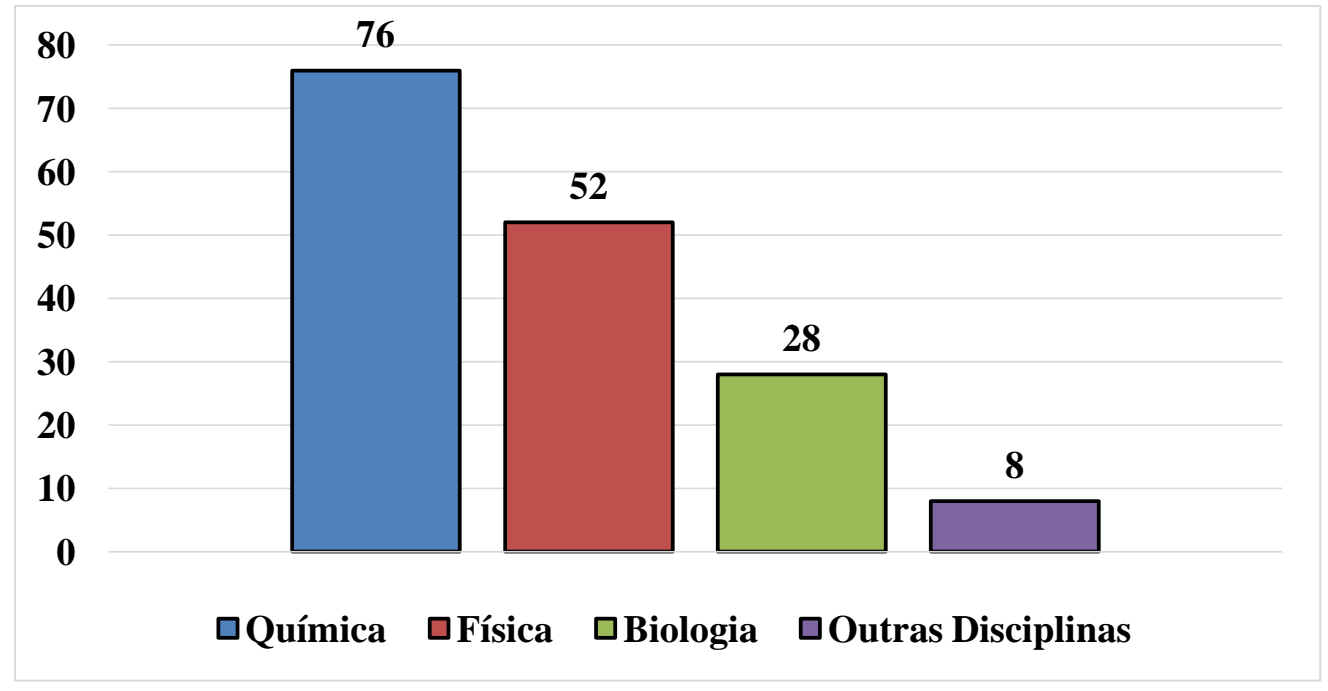

Gráfico 01: Em que disciplina você estuda (ou estudou) o átomo?

$\mathrm{Na}$ segunda questão podemos observar que os sujeitos identificaram uma relação do conceito de átomo nos componentes curriculares de Biologia e Física.

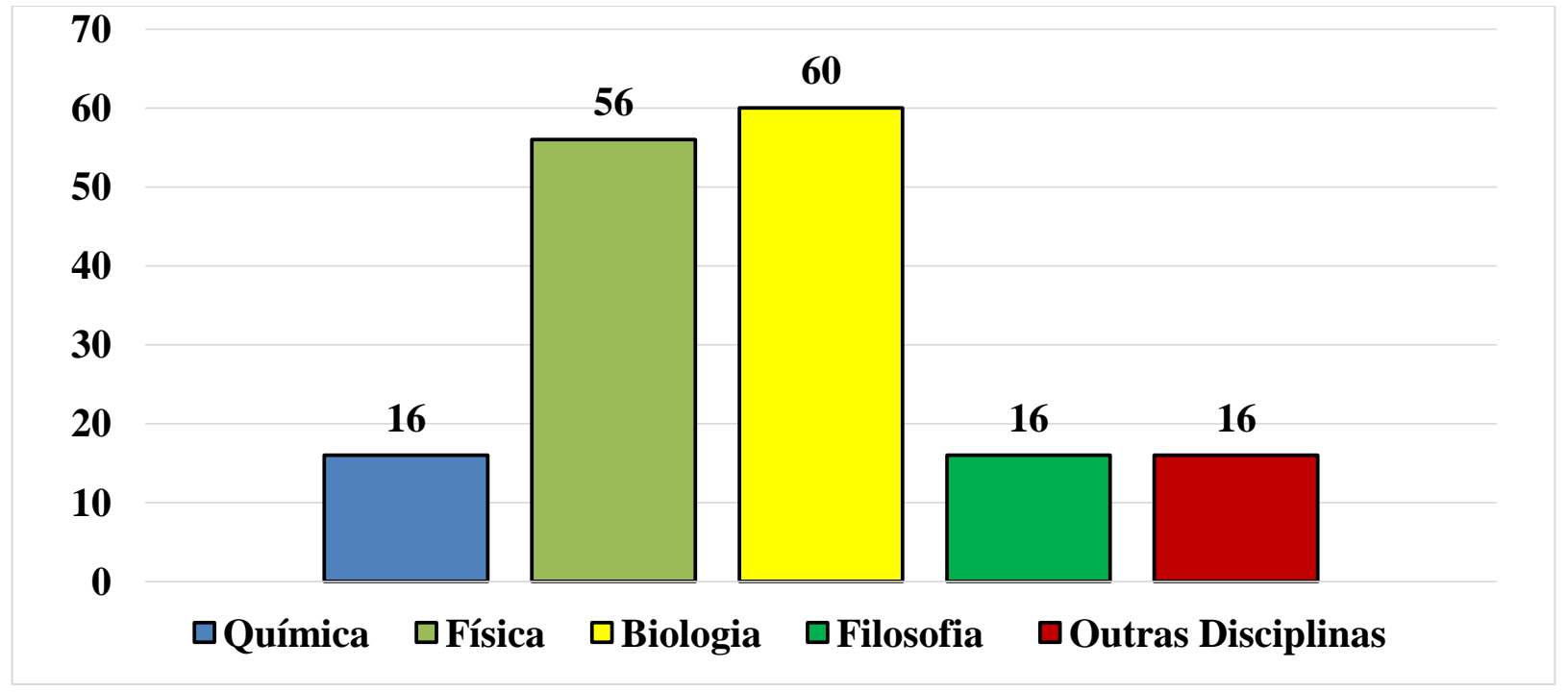

Gráfico 02: Você acha de deveria estudar o conceito de átomo em alguma outra disciplina? Qual ou quais?

Observamos, nesta segunda questão, as referências principalmente as disciplinas de física e de biologia o que de certa forma nos leva a concluir que o estudante relaciona estas disciplinas ao estudo do átomo. Contudo é interessante observarmos que estes estudantes perceberam esta relação com outras disciplinas como por exemplo a filosofia.

A terceira questão enfatiza a relação do átomo com o "dia-a-dia 


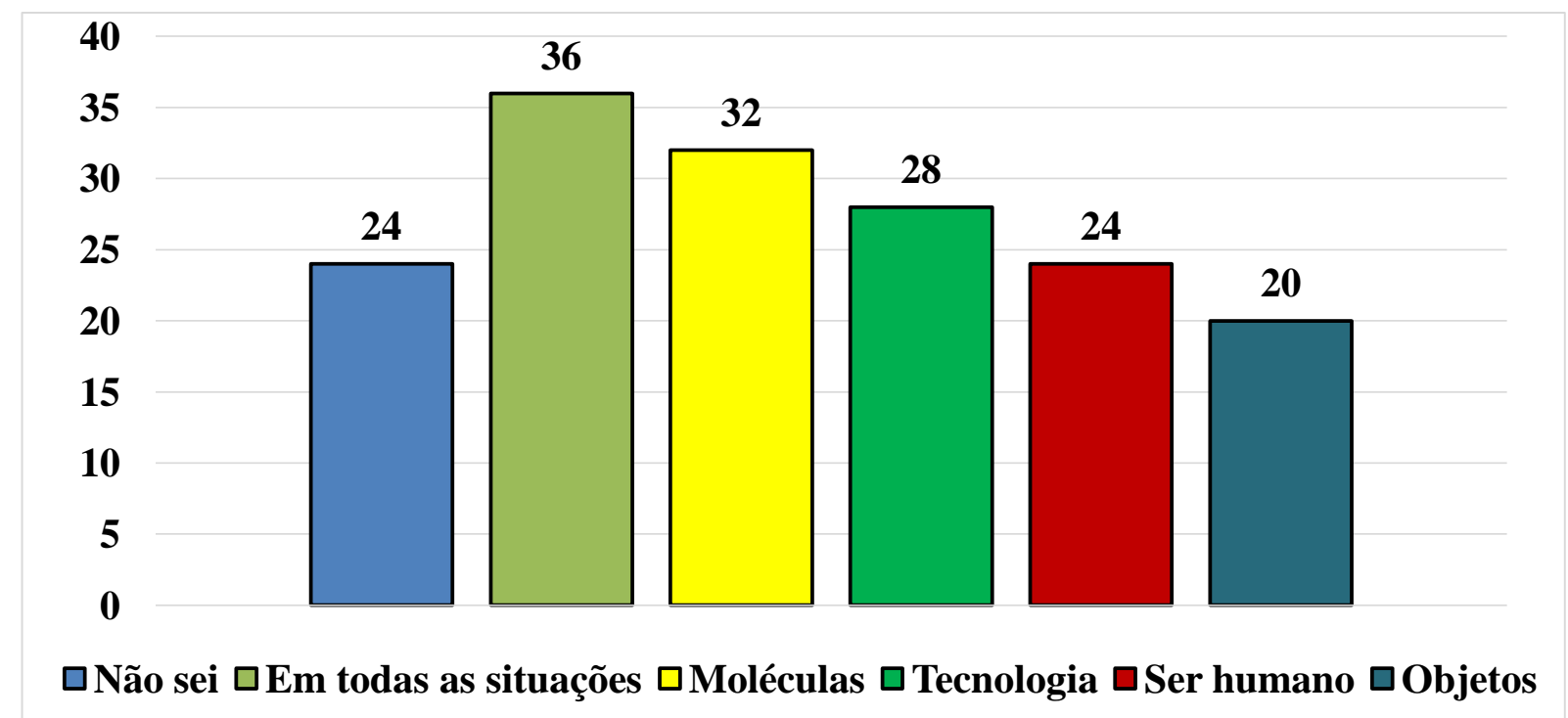

Gráfico 03: Qual a relação do átomo com o dia-a-dia?

Observando o gráfico 03, relacionado ao átomo na vida diária, percebemos que os estudantes participantes da pesquisa, declararam de uma maneira geral que os átomos estão em toda parte, uma vez que não houveram grandes diferenças entre o quantitativo relacionados a "todas as situações", "ser humano", "tecnologia", "moléculas" e "objetos".

A quarta questão, sobre “Qual a sua definição de Átomo?” os estudantes apresentaram uma definição aproximada a de Atkins e Jones (2006), em que o átomo fica sendo definido como a "menor partícula de um elemento que tem as propriedades químicas desse elemento, sendo assim uma partícula indivisível".

Na tabela 01, podemos observar que $75 \%$ dos sujeitos definiram como Atkins e Jones o conceito de Átomo.

\begin{tabular}{ll}
\hline Definição & Porcentagem em Alunos \\
\hline Partículas indivíseis & $51,2 \%$ \\
\hline Menor partícula & $24,4 \%$ \\
\hline São partículas elementares & $24,4 \%$ \\
\hline
\end{tabular}

Tabela 01: Qual é a definição de Átomo?

Análise das aulas - Conceito de átomo 
Para identificação do conceito de átomo foram observadas aulas dos componentes curriculares de Química, Física e Biologia. Na tabela categorizamos algumas das falas por disciplinas. Para analises das aulas utilizamos alguns pontos de identificação: (1) Como o conceito de átomo está sendo abordado; (2) Quais contribuições o professor trás para sua aula; (3) Qual foi a relação interdisciplinar;

\begin{tabular}{|c|c|c|}
\hline \multicolumn{3}{|l|}{ Vivências das Aulas } \\
\hline Química & Física & Biologia \\
\hline $\begin{array}{l}\text { - Na fala do professor } \\
\text { " } Q \text { ”: O átomo consiste } \\
\text { numa menor partícula, } \\
\text { são indivisíveis onde o } \\
\text { conjunto forma uma } \\
\text { molécula; }\end{array}$ & $\begin{array}{l}\text { - Na fala do professor } \\
\text { "F”: Os átomos são peças } \\
\text { fundamentais da matéria, e } \\
\text { estão presentes em tudo; }\end{array}$ & $\begin{array}{l}\text { - Na fala do professor } \\
\text { “B”: Os átomos são } \\
\text { partículas elementares e } \\
\text { indivisíveis; }\end{array}$ \\
\hline $\begin{array}{l}\text { - Contextualizou } \\
\text { estudo, citando os } \\
\text { efeitos dos fogos de } \\
\text { artifícios afirmando que } \\
\text { na presença de uma } \\
\text { chama os átomos se } \\
\text { tornam visíveis; }\end{array}$ & $\begin{array}{l}\text { - Enfatizou que nos átomos } \\
\text { existem partículas } \\
\text { elementares como os } \\
\text { prótons, os elétrons e os } \\
\text { nêutrons. }\end{array}$ & $\begin{array}{l}\text { - Abordou a relação dos } \\
\text { átomos presentes no } \\
\text { corpo humano e que os } \\
\text { mesmos formam as } \\
\text { moléculas que estão } \\
\text { presentes em nosso } \\
\text { organismo em nosso dia- } \\
\text { a-dia }\end{array}$ \\
\hline $\begin{array}{l}\text { - Afirmou também que o } \\
\text { átomo é uma partícula } \\
\text { indivisível; }\end{array}$ & $\begin{array}{l}\text { - Afirmou que alguns } \\
\text { materiais são carregados } \\
\text { positivamente } \\
\text { negativamente; }\end{array}$ & $\begin{array}{l}\text { - Relacionou o átomo } \\
\text { com a anatomia e } \\
\text { fisiologia humana }\end{array}$ \\
\hline
\end{tabular}

Tabela 02: Categorização das aulas de Química, Física e Biologia

\section{CONCLUSÕES}

Diante dos resultados obtidos no decorrer de nossa pesquisa, verificamos que grande parte dos sujeitos investigados, apresentam a concepção de átomo, como partícula indivisível e que o estudo de tal partícula, segundo os mesmos, esta relacionando primeiramente à disciplina de 
química, não descartando outras disciplinas. As disciplinas de física e biologia também aparecem como disciplinas que estudam o átomo.

Apesar do reconhecimento deste estudo em outras disciplinas não foram identificadas práticas interdisciplinares que possibilitassem ao educando, uma percepção integrada do átomo entre as diversas disciplinas.

Quanto à correlação do átomo com os fenômenos que norteiam o dia-a-dia do aluno, apesar do reconhecimento por parte dos mesmos sobre o fato de o átomo estar presente em todas as situações, da vida diária, houve poucas contextualizações por parte dos mesmos além daquelas observadas durante a aula de química e a de biologia.

A experiência da realização de uma pesquisa como esta, é gratificante e esclarecedora, pois nos possibilita realizar reflexões a cerca de conceitos como é o caso dos átomos, que são abordados de forma paralela ao longo de toda a disciplina ou até mesmo ao longo de todo o curso, contudo nos conduz a refletir sobre o quanto seria importante a prática de abordagens interdisciplinares, possibilitando a docentes e discentes o estabelecimento de percepções holísticas de conceitos essenciais na construção de conceitos no ensino das ciências.

Afirmamos aqui a intenção de continuarmos nossa pesquisa de forma a colocarmos em prática abordagens interdisciplinares que possibilitem a ampliação e renovação das concepções de todos os envolvidos em nossa pesquisa, através da realização de grupos de estudos que venham a oportunizar discursões do ponto de vista de várias disciplinas tomando assim um enfoque interdisciplinar o que nos possibilita uma compreensão integralizada sobre a constituição e as reações químicas de nossa vida diária.

\section{REFERÊNCIAS}

ATKINS, P.; JONES, L. Princípios de Química: Questionando a Vida Moderna e o Meio Ambiente. $3^{\text {a }}$ Edição, Porto Alegre: Bookman, 2006.

BARDIN, L. A análise de conteúdo. Lisboa: Edições 70, 2011.

BUENO, F. R. A revolução organísmica: Uma análise sobre a mudança de paradigma www.duplipensar.net/artigos/2004-Q4/revolucao-organismica.html Publicado em 18.12.2004

CAPRA, Fritjof. O ponto de mutação: A Ciência, a Sociedade e a Cultura emergente. São Paulo: Editora Cultura, 1995

FAZENDA, Ivani Catarina Arantes. Interdisciplinaridade: história, teoria e pesquisa. 10 ed. Campinas: Papirus, 2002. p. 143 
FAZENDA, I. C. A. Integração e Interdisciplinaridade no Ensino Brasileiro: Efetividade ou Ideologia. São Paulo: Edições Loyola. 1979

GOMES, J. P. H; OLIVEIRA, O. B. O. Obstáculos epistemológicos no ensino de ciências: um estudo sobre suas influências nas concepções de átomo. Ciências \& Cognição, Rio de Janeiro, v. 12, p 96-109, 2007.

JAPIASSU, H. (1976). Interdisciplinaridade e Patologia do Saber. Imago: Rio de Janeiro;

JUNIOR, M. B. M. S.; MELO, M. S. T.; SANTIAGO, M. E.; A análise de conteúdo como forma de tratamento dos dados numa pesquisa qualitativa em Educação Física escolar. Porto Alegre, v. 16, n. 03, p. 31-49, julho/setembro de 2010.

KLEIN, Julie Thompson. Ensino interdisciplinar: didática e teoria. In: FAZENDA, I. C. A. (org.). Didática e interdisciplinaridade.6 ed.Campinas: Papirus, 2001, p.109-132.

MORTIMER, E. F. Construtivismo, Mudança Conceitual e Ensino de Ciências: Para onde vamos. Investigações em Ensino de Ciências. Porto Alegre. v. 1, p. 20-39, 1996.

ROCHA, J. F. M.; MORENO, R. R. de M.; O Átomo Quântico. Revista Ciência Hoje; 305; Vol. 51. Instituto de Física, Universidade Federal da Bahia; 2013

ROMANELLI, L. I. O papel mediador do professor no processo de ensino-aprendizagem do conceito átomo. Química Nova na Escola, São Paulo. v.3, p. 27-31, 1996.

SANDRI, I. G.; MARTINS. J. A.; PIEMOLINI-BARRETO L. T.; VILLAS-BOAS V,; Concepções Prévias do Modelo de Átomo dos Alunos de Engenharia de Alimentos e Engenharia Química; XXXIX. Congresso Brasileiro de Educação em Engenharia. Blumenau, SC, 2011. 